\title{
THE EFFECTS OF CONTINUOUS PRESSURE BREATHING ON KIDNEY FUNCTION ${ }^{1}$
}

\author{
BY D. R. DRURY, J. P. HENRY, AND JOSEPH GOODMAN \\ (From the Departments of Physiology and Aviation Medicine, The University of Southern \\ California, Los Angeles, California)
}

(Received for publication February 18, 1947)

Continuous pressure breathing is a technique developed to increase the alveolar oxygen tension by breathing oxygen at higher than ambient pressure. In other words the pressure within the alveoli of the lungs is higher than that outside the chest wall. It is found that as much as $16 \mathrm{~mm}$. $\mathrm{Hg}$ of such extra pressure can be tolerated for periods of 30 to 60 minutes by the average healthy man. However, as the extra pressure is increased above this figure, evidence of a deleterious effect upon the circulation becomes increasingly apparent. At pressures of 25 to $40 \mathrm{~mm}$. $\mathrm{Hg}$ circulatory collapse and fainting become frequent. Often in cases in which this does not ensue there may develop sensations of impending collapse with pallor and sweating, necessitating termination of the test. Although the blood pressure remains above the control level the pulse is small and difficult to feel and the cardiac output is diminished (1). When using these higher pressures not only is much blood pooled in the veins of the arms and legs but also there is a progressive hemoconcentration due to the passage of fluid from the blood stream into the tissue spaces under the influence of the raised intravascular pressure (2). A considerable fraction of the total blood volume is thus more or less sequestrated from the general circulation under these conditions and when collapse ensues it is in large part due to decreased effective blood volume. The actual total volume of blood thus isolated cannot be readily assessed and there is need of a reliable but simple test which could be used to assay the impairment of circulation induced by pressure breathing.

With this aim in view we studied the blood pressure changes occurring during continuous pressure breathing. This was determined in the usual manner on the arm. Such an approach proved unsatisfactory since a fall in the pressure was usually

1 The work described in this paper was done under a contract, recommended by the Committee on Medical Research, between the Office of Scientific Research and Development and the University of Southern California. only observed when the subject was on the verge of syncope. Otherwise the blood pressure was the same as the control value or, as was usual, it was somewhat elevated. We then decided to investigate the value of a determination of the changes in kidney function produced by pressure breathing.

\section{METHOD}

The specific function of the kidney studied was its capacity to excrete urea. This information is obtained by determining the rate of urea excretion during any period and dividing this by the blood urea concentration at the time, thus obtaining a value essentially the same as the kidney clearance. Urea was chosen because of the accuracy with which it can be determined and the constancy of its clearance in a given individual under standard conditions. In addition it has been shown to be responsive to physiological changes in the circulatory system which take place in such conditions as severe exercise (3) and hemorrhage (4). The test was carried out as follows: The subject went without breakfast in the morning and drank a liter of water on rising and $500 \mathrm{ml}$. per hour thereafter until the completion of the test. Within 2 hours a good diuresis usually developed and the determination of function was then started. The subject emptied his bladder and noted the exact time. Thirty minutes later a blood sample was taken and 30 minutes after that, the first urine collection was made. Immediately after completion of this 1-hour control period the subject pressure-breathed for 30 minutes.

Either compressed air or pure oxygen was used and applied by an Army A-13 pressure-breathing mask. Pressures were measured at the mask and determined by observing a manometer connected to a tube introduced into the mask. In order to ensure a full application of the pressure the subjects were instructed not to restrict the passage of gas to the lungs by closure of the glottis. No counter-pressure was applied to the body. A blood sample was taken midway through the pressure-breathing period and the urine collected at the end. Observations were continued during the post-pressure-breathing period for 2 or 3 consecutive hourly periods. Thus each test involved a series of 4 or 5 periods which together occupied a whole morning.

Four subjects were studied with repeated tests. On any given test the breathing pressure remained constant throughout the pressure-breathing period. Duplicate runs 


\section{TABLE I}

Representative table showing the decrease in kidney function during a 30-minute period of breathing at $40 \mathrm{~mm}$. $\mathrm{Hg}$ super added pressure

The equation below illustrates the method of calculating the reduction in kidney function produced by the pressure breathing and the figures so obtained are those depicted in Figures 1, 2, 3, and 4 . In addition the table illustrates the lag in return of function after pressure breathing is stopped.

June 10, 1946

Subject: E. K.

Pressure: $40 \mathrm{~mm}$. $\mathrm{Hg}$

\begin{tabular}{|c|c|c|c|c|c|}
\hline Period & Time & $\begin{array}{l}\text { Urine } \\
\text { urea }\end{array}$ & $\begin{array}{c}\text { Blood } \\
\text { urea }\end{array}$ & $\begin{array}{c}\text { Urea } \\
\text { clearance }\end{array}$ & $\begin{array}{c}\text { Kidney } \\
\text { function } \\
\text { (control) }\end{array}$ \\
\hline & $\min$. & $\underset{h r}{m g}$. per & $\begin{array}{l}\text { mgm. per } \\
100 \mathrm{ml} \text {. }\end{array}$ & $\begin{array}{l}\text { ml. per } \\
\text { hr. }\end{array}$ & per cent \\
\hline $\begin{array}{c}1 \\
2 \\
\text { P.B. }\end{array}$ & 68 & 906 & 19.8 & 4580 & 100.0 \\
\hline $\begin{array}{c}\text { Period } \\
3 \\
4\end{array}$ & $\begin{array}{l}32 \\
31 \\
47\end{array}$ & $\begin{array}{l}426 \\
106 \\
847\end{array}$ & $\begin{array}{l}18.3 \\
18.6 \\
18.9\end{array}$ & $\begin{array}{r}2330 \\
570 \\
4480\end{array}$ & $\begin{array}{l}50.9 \\
12.4 \\
97.8\end{array}$ \\
\hline
\end{tabular}

$\frac{\text { Urea clearance Per. } 2}{\text { Urea clearance Per. } 1}=\frac{23.3}{45.8}=50.9$ per cent.

were carried out on all subjects using $10,20,30$, and 40 mm. Hg mask pressure.

The urea in the blood and urine was determined by the urease technique of Addis (5). The rate of excretion of urea was calculated on a per hour basis for each period (pre-pressure-breathing, pressure-breathing and the two post-pressure-breathing periods). This hourly rate was divided by the urea concentration of $\mathrm{mgm}$. per cent found in the blood taken at the middle of the period. (Determiations of the blood urea showed no significant change throughout the morning of a given test.) The quotient so obtained was taken as the measure of kidney function during any particular period. The value for the kidney function during the pre-pressure-breathing period of a given test was taken as 100 per cent and the kidney functions found during the succeeding periods were calculated on this basis.

\section{RESULTS}

It is apparent from Table $I$ that the pressure breathing has caused a decrease in kidney function not only during the period of active pressure breathing (Period 2) but also during the postpressure-breathing period (Period 3). In Figure 1 are shown the results of a series of such tests on the same subject, each circle representing the reduction in kidney function during the pressurebreathing period of one test. Figures 2,3 , and 4 represent similar series of tests for 3 other subjects. It will be seen that at $40 \mathrm{~mm}$. $\mathrm{Hg}$ pressure the function was reduced to between 20 to 50 per cent of normal.

A pressure of $10 \mathrm{~mm}$. $\mathrm{Hg}$ shows practically no effect; but, beginning with $20 \mathrm{~mm}$. $\mathrm{Hg}$ there is a definite functional depression which becomes greater with successively higher pressures. In many experiments the function remains depressed for an hour or more after the resumption of normal breathing. Figure 5 illustrates this point. The continuation of the depression of urine volume and urea clearance during the first post-pressurebreathing period is marked. It may be noted that when the urine volume decreases to levels of $0.1 \mathrm{ml}$. per min., as it did in the post-pressure-breathing

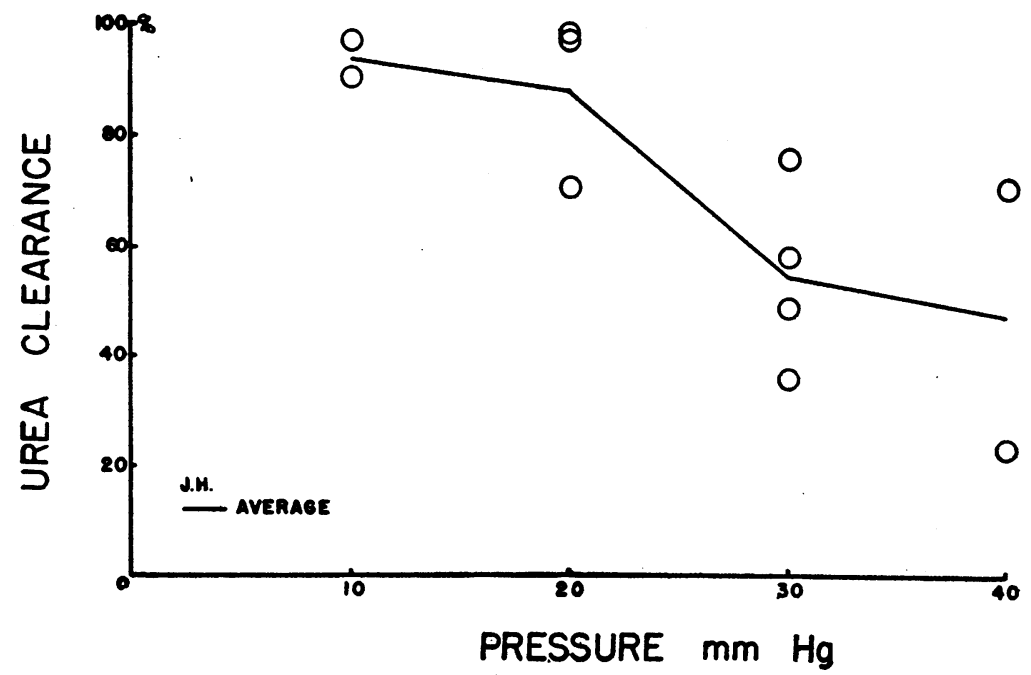

FIG. 1 
EFFECTS OF PRESSURE BREATHING ON KIDNEY FUNCTION

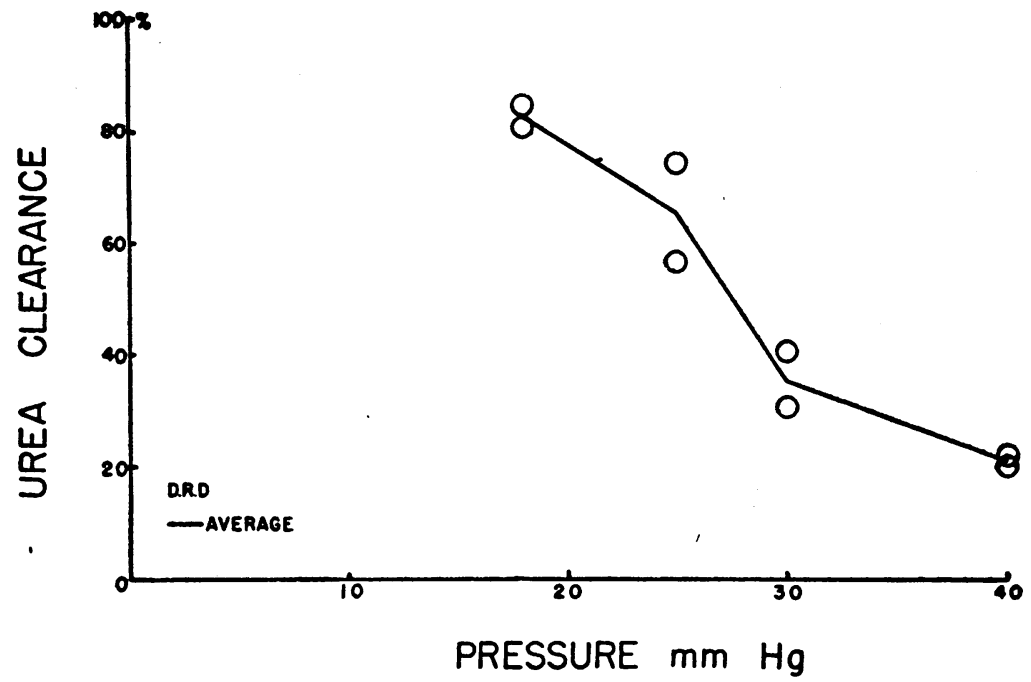

Frg. 2

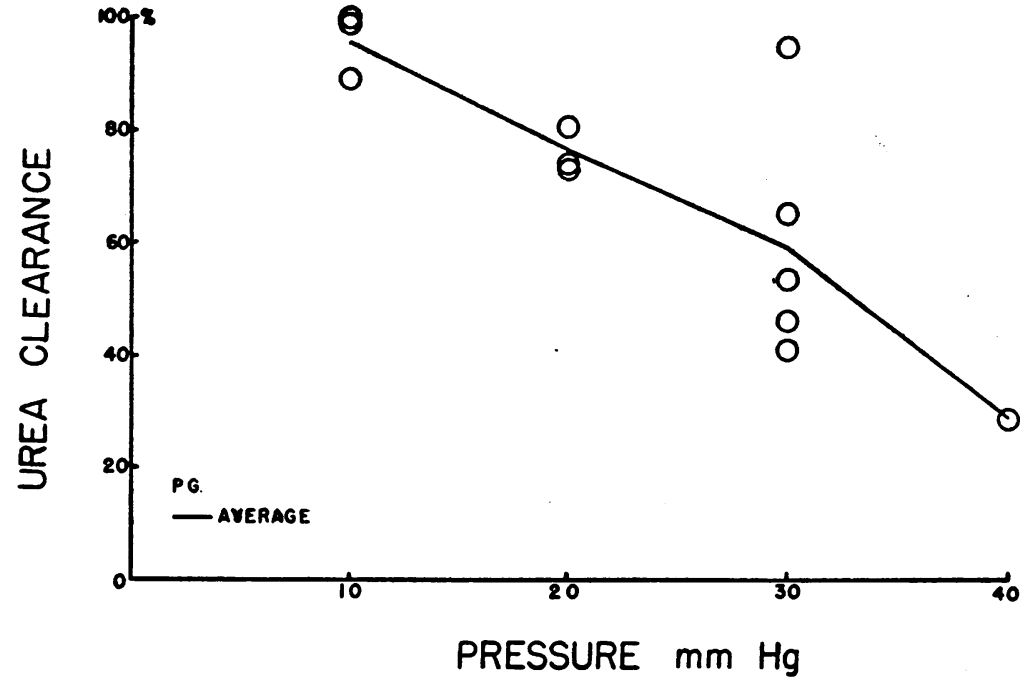

Fig. 3

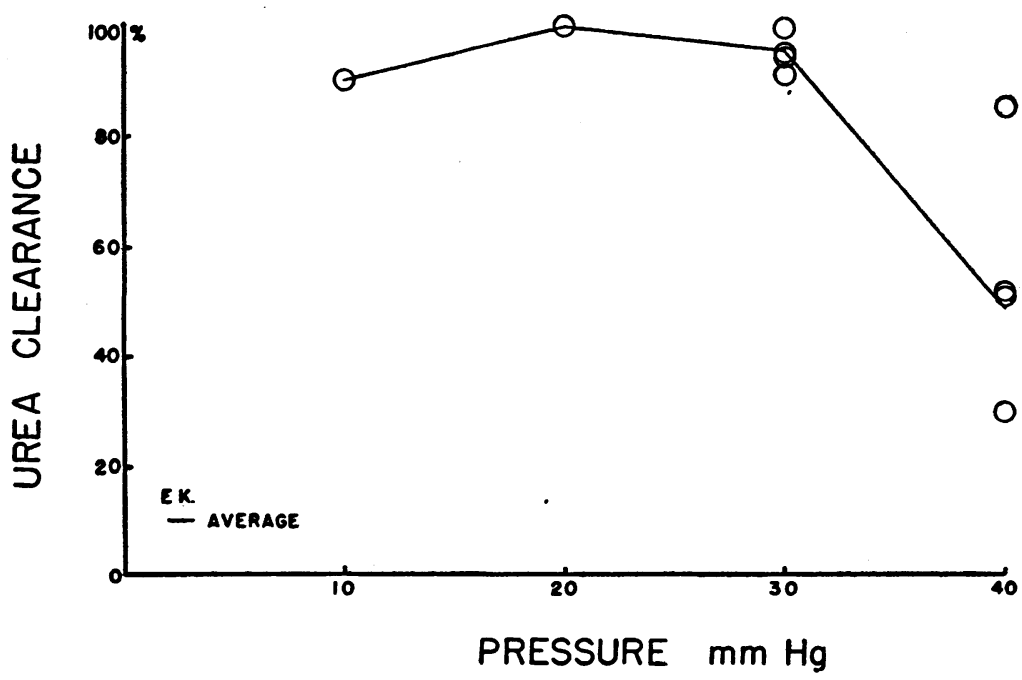

FIG. 4 
period represented in this case, the urea clearance determination becomes less accurate (6). Figure 6 illustrates a case in which the function during the post-pressure-breathing period is markedly di- minished below that during the pressure-breathing period. However it must be remembered that the charts give only the average of function during each period. It is not possible to determine the

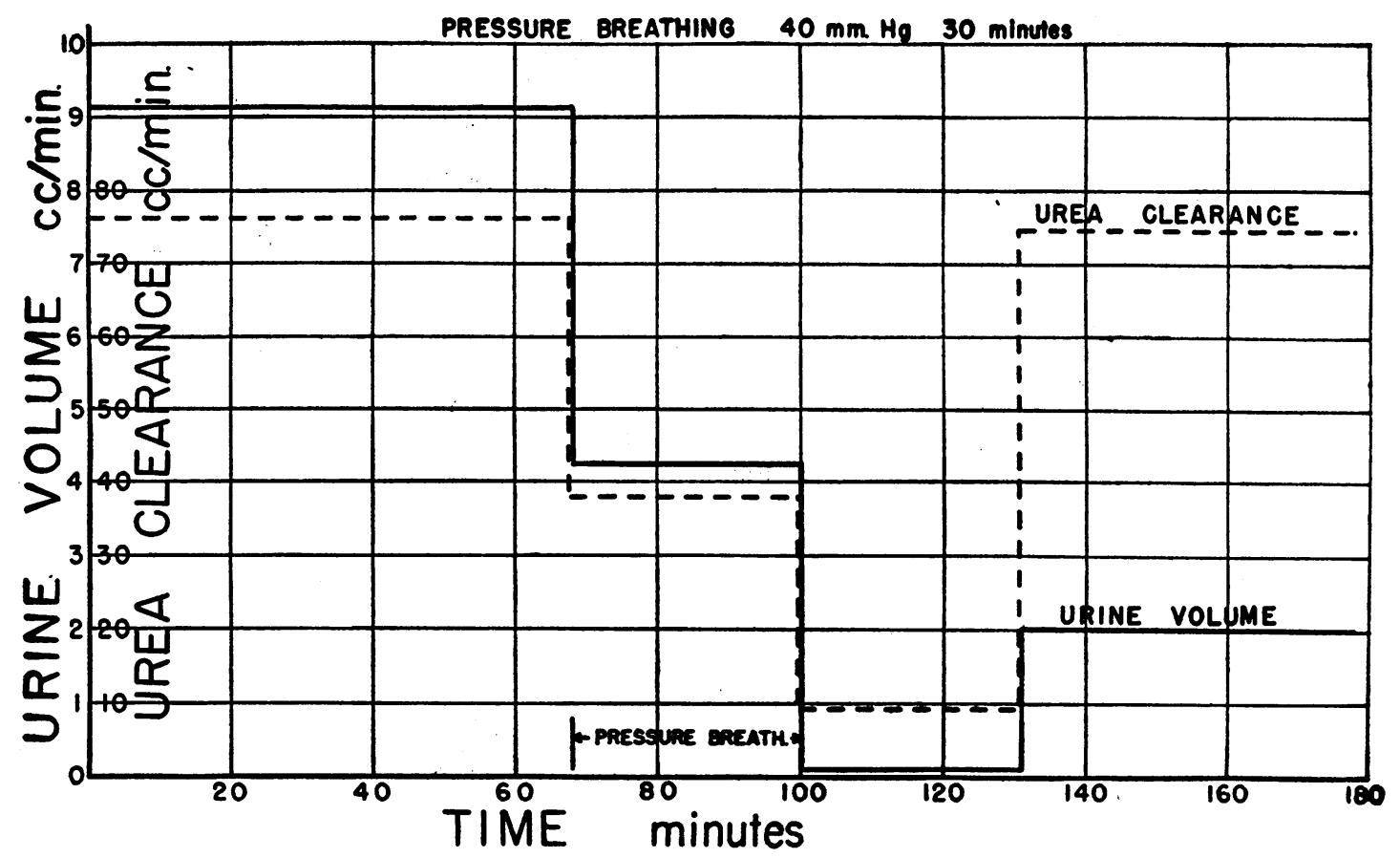

FIG. 5

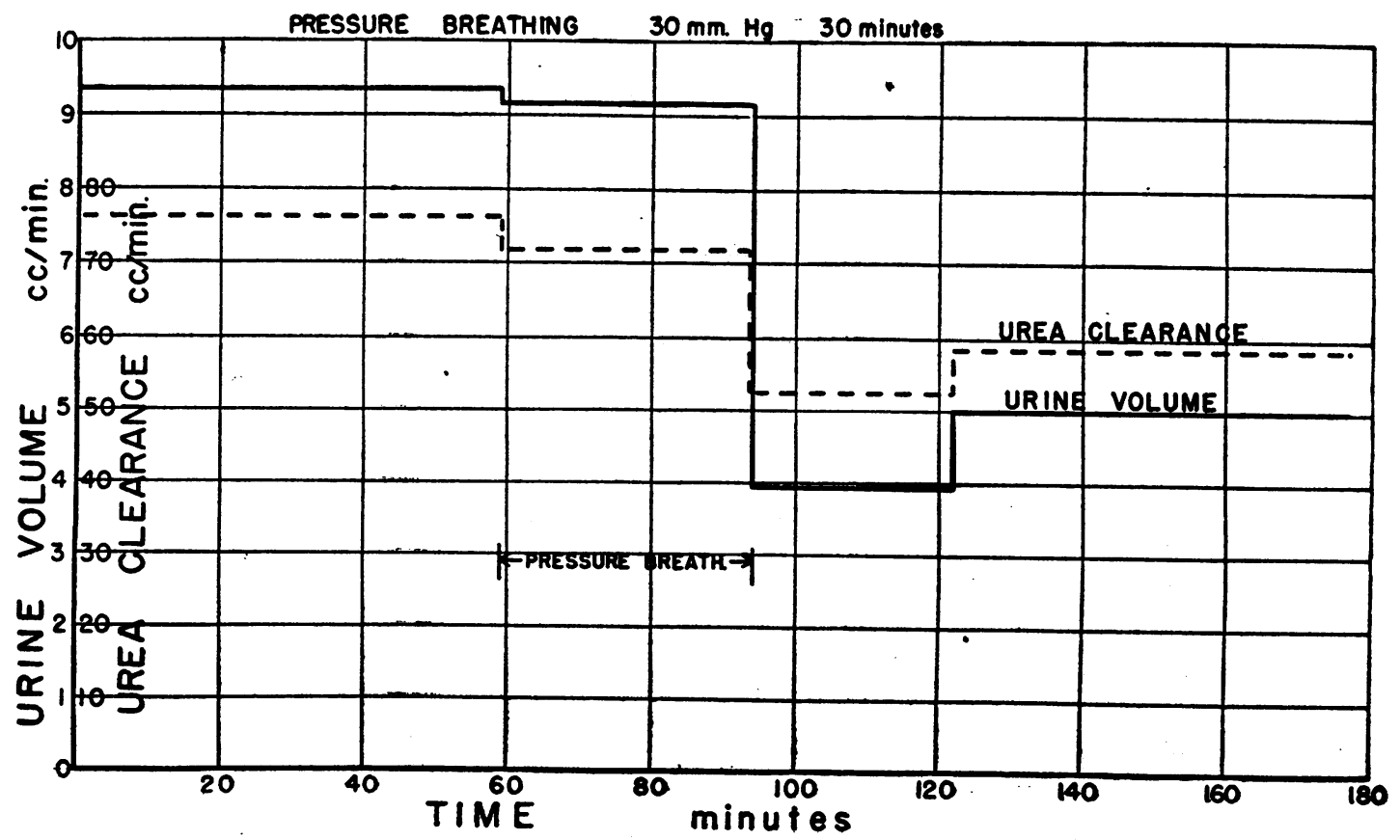

Fig. 6 


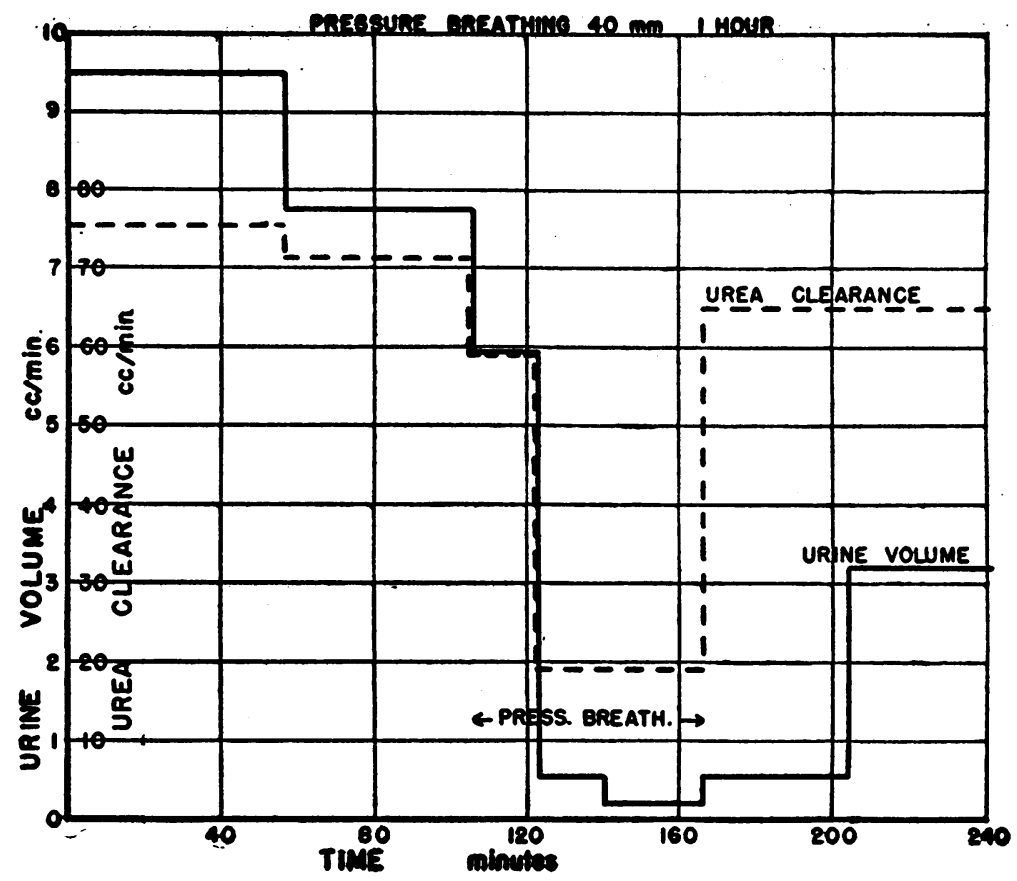

Fra. 7

function for each minute. Therefore, for the case shown in Figure 6, it does not follow that the function during the last minute of the pressure-breathing period was actually lower than that of the first minute of the after period.

This prolonged depression in function following the pressure breathing suggested that there is a certain "inertia" of function prolonging response beyond the causal period. The question arose whether there was a corresponding delay in the decrease in function at the onset of the pressurebreathing period. To test this, an experiment was carried out in which the subject continued pressurebreathing for 1 hour (Figure 7). This period was subdivided into 3 periods in each of which a separate function determination was carried out. It is apparent that marked depression does not occur immediately and that during the first 15 to $20 \mathrm{~min}$ utes the function remains relatively high.

\section{DISCUSSION}

Reference may be made to some of the work that has been published in recent years indicating that the kidney circulation is early reduced in conditions that embarrass the general circulation ( 7 to 9). The results of these workers in addition to that of others support the view that a measurement of kidney function can be used to determine the degree of circulatory stress. Our findings are definitely in line with this. Care must be taken in every particular case to evaluate the action of additional factors, such as kidney disease and specific renal toxins, which can affect kidney function. Pain also has been shown to diminish renal function (10). The exact mechanism of its action on the kidney has not yet been decided. There was some degree of discomfort in breathing at the higher pressures and this action may have contributed to the reduction in kidney function seen here.

Pressure breathing may be considered a useful experimental method by which definite circulatory stress can be produced rapidly and with relative safety. We feel that the degree of depression of kidney function that we obtained is proportional to the magnitude of the circulatory stress produced. Used in this way the procedure has been of some value to us in determining the efficacy of supportive measures which may be used to combat the deleterious effect of pressure breathing on the circulation.

Our results indicate that pressure breathing of moderate magnitude can be tolerated by normal healthy individuals for appreciable times, i.e., $1 / 2$ to 1 hour. The higher pressures cannot be tolerated 
so long. We believe that pressure breathing might be used as a test of circulatory fitness. It would seem probable that individuals with reduced circulatory reserve such as is found in persons employed in sedentary occupations would be affected by those lower pressures which do not have very much effect on physically active people in good circulatory condition. The degree of effect on the circulation could, we believe, be readily estimated by determining the effect on kidney function. Not only does such a test give an opportunity for quantitative measurements but it can be carried out without producing the alarming and uncomfortable symptoms associated with circulatory collapse.

In conditions in which the amount of actively circulating blood is reduced by loss of fluid or pooling in inactive areas the vasomotor system will cut down on blood flow through regions that can tolerate this temporarily. The circulation through the kidney behaves somewhat like that through the skin in this respect and kidney blood flow can be reduced to $1 / 10$ to $1 / 20$ of normal resting volumes when strain is imposed on the circulatory system (11). The kidney circulation can in fact serve as an important reserve for the general vascular system. Not only is a certain volume of blood made directly available by the reduction in kidney volume following renal vaso-constriction but in addition it may be noted that normally $1 / 4$ of the blood in the great veins, heart, lungs and aorta is concerned with the renal circulation and that when blood flow through the kidney is reduced this blood can then be utilized to serve the vital areas of the body.

The question might be raised as to the "wisdom of the body" in sacrificing kidney function in conditions putting a strain on the circulatory system. If this strain is not prolonged beyond a few hours then cutting down of the blood flow through the kidney would seem to be a proper mechanism to help tide the circulatory system over a temporary embarrassment. The concomitant temporary reduction in kidney function would not be harmful. Thus, a normal individual can remain for at least a day without kidney function without showing otherwise any serious disturbance. Upon the resumption of activity this organ can quickly make up for the period of inactivity. We might speak of the body going into a "renal debt" in order to help the circulatory system carry on during a pe- riod of temporary stress. Naturally there should not be complete cessation of renal blood flow for any appreciable duration since this may lead to irreparable kidney damage if lasting more than 1 hour (12).

However, such a mechanism is not without its dangers. If the circulation cannot be established within a reasonable time the continued impairment of kidney function would lead to serious consequences. This can be the case in prolonged traumatic shock and infectious diseases causing peripheral circulatory failure (7). It is probable that continued dehydration can also be dangerous for this reason. Finally if renal function had already been inadequate for a prolonged period before the imposition of circulatory stress then a further reduction in renal blood flow even for a few hours could be a serious matter.

The lag in the return of kidney function to normal after cessation of pressure breathing is of interest. It represents to some extent the time required for the circulatory system to return to normal. However, this period is normally very brief since the blood pooled in the limbs is immediately available for active circulation on the cessation of pressure breathing. Some of the delay is due to the time (10 to 20 minutes), needed for return to the blood of fluid that had escaped into the extravascular compartment. In addition, time is needed for the kidney tissue to reestablish itself after proper blood flow has been started again. Thus Selkurt (13) has shown that after clamping the renal arteries for 20 minutes the return of kidney function to normal was delayed at least 2 to 3 hours after release of the artery, whereas direct measurement of blood flow showed a much more rapid restitution.

An additional important mechanism, however, which may account for much of the prolonged lag lies in the possibility of hormonal activity. The urine volume changes during the test suggest that an antidiuretic (presumably posterior pituitary) action may enter into the picture. Since pituitrin depresses urea clearance in addition to the urine volume, posterior pituitary activity may also play a significant part in the lag in return of kidney function to normal after cessation of pressure breathing (3). That this hormone is involved is suggested by the report of Brun et al (14) who studied kidney function during the circulatory collapse pro- 
duced by prolonged maintenance of the upright position on the tilt table. They found that the inulin and diodrast clearances were reduced during the period of collapse and for periods of a quarter of an hour or more thereafter. The subjects drank large amounts of water so that they were well hydrated and were excreting large volumes of urine prior to the collapse. Following collapse the urine volume was markedly diminished and remained low for periods of 1 hour or more. They present evidence to support the view that this reduction in urine volume is due to increased secretion of an antidiuretic hormone. Our results are similar with respect to changes in urine volume. It should be noted that the urine volumes in our cases were depressed for a considerable period after the pressure breathing and that the urea concentration in the urine was increased at this time, although the clearance was depressed. Our findings differ from those of the above mentioned workers to the extent that we did not have symptomatic circulatory collapse and that the blood pressure was well maintained, whereas their subjects showed very low blood pressures during the period of reduced kidney function.

\section{SUMMARY}

1. Four subjects submitted to 30-minute periods of continuous pressure breathing at 10,20 , 30 and $40 \mathrm{~mm}$. $\mathrm{Hg}$ above ambient pressure showed a progressive reduction of kidney function which, with the higher pressures, reached approximately 20 to 50 per cent of normal values.

2. This depression in function persisted for 1 to 2 hours after the cessation of the pressure-breathing period. The possible mechanism of this continued depression is discussed.

3. These results support the view that estimations of kidney function may be used as a measure of the circulatory stress induced by a reduction of effective blood volume.
4. It is suggested that pressure breathing should be investigated as a test of circulatory fitness by employing estimations of disturbance of kidney function as an index of the extent of its effect upon the circulatory system.

\section{BIBLIOGRAPHY}

1. Cournand, Andre. Personal communication.

2. Henry, J. P., and Meehan, J., Estimations of the decrease in effective blood volume when pressure breathing, to be published.

3. Addis, T., and Drury, D. R., The rate of urea excretion; effect of various other factors than blood urea concentration on rate of urea excretion. $J$. Biol. Chem., 1923, 55, 629.

4. Selkurt, E. E., Renal blood flow and renal clearance during hemorrhagic shock. Am. J. Physiol., 1946, 145, 699.

5. Addis, T., Urea determinations in blood and urine. J. Lab. \& Clin. Med., 1925, 10, 402.

6. Peters, J. P., and Van Slyke, D. D., Quantitative Clinical Chemistry. Williams and Wilkins, Baltimore, 1931, Vol. 1, p. 345.

7. Maegraith, B. G., Havard, R. E., and Parsons, D. S., Renal syndrome of wide distribution induced possibly by renal anoxia. Lancet, 1945, 2, 293.

8. Lauson, H. D., Bradley, S. E., and Cournand, A., The renal circulation in shock. J. Clin. Invest., 1944, 23, 381.

9. Phillips, R. A., Dole, V. P., Hamilton, P. B., Emerson, Kendall., Archibald, R. M., and Van Slyke, D. D., Effects of acute hemorrhagic and traumatic shock on renal function of dogs. Am. J. Physiol., 1946, 145, 314.

10. Wolf, G. A., The effect of pain on renal function. A. Research Nerv. \& Ment. Dis., Proc., 1943, 23, 358.

11. Cournand, A., et al., Studies of the circulation in clinical shock. Surgery, 1943, 13, 964

12. Scarff, R. W., and Keele, C. A., The effect of temporary occlusion of the renal circulation in the rabbit. Br. J. Exper. Path., 1943, 24, 147.

13. Selkurt, E. E., Comparison of renal clearances with direct renal blood flow under control conditions and following renal ischemia. Am. J. Physiol., 1946, 145, 376.

14. Brun, C., Knudsen, E. O. E., and Raaschou, F., Kidney function and circulatory collapse. J. Clin. Invest., 1946, 25, 568. 